\title{
Correction: Trends in relative survival in patients with a diagnosis of hepatocellular carcinoma in Ontario: a population-based retrospective cohort study
}

The research article that appeared in CMAJ Open May 14, $2015,{ }^{1}$ contained an error in the second sentence of the Results section of the Abstract and had incorrect labelling in Figure 2.

The second sentence in the Results section of the Abstract read "Improvements in 1-year relative survival were observed across all age groups over time: the highest was among those patients aged 60 years or younger who had a diagnosis of HCC during 2005-2009, with 1-year survival exceeding 50\% for both sexes." This sentence should read "Improvements in 1-year relative survival were observed across all age groups over time: the highest was among those patients less than 60 years of age who had a diagnosis of HCC during 2005-2009, with 1 -year survival exceeding $50 \%$ for both sexes."
In Figure 2, the labels in the legends for both graphs were reversed (green label represented males and blue label represented females). The green label should represent females and the blue label should represent males.

CMAF Open apologizes for any inconvenience these errors may have caused.

\section{Reference}

1. Thein H-H, Khoo E, Campitelli MA, et al. Trends in relative survival in patients with a diagnosis of hepatocellular carcinoma in Ontario: a populationbased retrospective cohort study. CMAJ Open 2015;3:E208-16

CMAJ Open 2015. DOI:10.9778/cmajo.20150109 